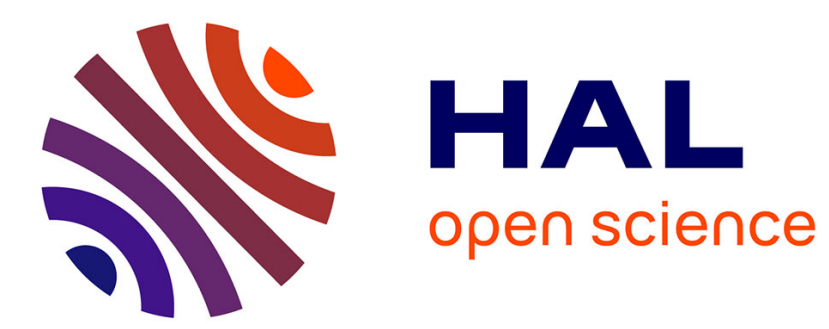

\title{
Price Fairness versus Pricing Fairness
}

\author{
Jean Michel Chapuis
}

\section{To cite this version:}

Jean Michel Chapuis. Price Fairness versus Pricing Fairness. Revenue \& Yield Management eJournal, 2012, pp.12. 10.2139/ssrn.2015112 . hal-00694108

\section{HAL Id: hal-00694108 \\ https://hal.science/hal-00694108}

Submitted on 3 May 2012

HAL is a multi-disciplinary open access archive for the deposit and dissemination of scientific research documents, whether they are published or not. The documents may come from teaching and research institutions in France or abroad, or from public or private research centers.
L'archive ouverte pluridisciplinaire HAL, est destinée au dépôt et à la diffusion de documents scientifiques de niveau recherche, publiés ou non, émanant des établissements d'enseignement et de recherche français ou étrangers, des laboratoires publics ou privés. 


\section{Price Fairness versus Pricing Fairness}

\section{Jean Michel Chapuis}

University of Paris 1 Panthéon-Sorbonne,

IREST, Centre Albert Châtelet, 6 rue Jean Calvin, 75005 Paris, France.

E-mail address: jchapuis@free.fr

March 2012

Abstract: This research note discusses the distinction between these two concepts of perceptions of fairness, based on the theory of distributive justice and procedural justice, in order to helps understand consumer behavior. With a sample of 250 tourists in French Polynesia and a structural equation model, tourists do not confuse price fairness and pricing fairness. The theoretical implications are that future research should use two distinct scales. For managers, the study suggests that the attention devoted to explaining the fairness of the pricing has more impact on consumer satisfaction than some attempts to explain the price.

Keywords: consumer perceptions, price fairness, pricing fairness, tourism study. 


\section{Introduction}

Long haul trips are usually book well in advance of departure, as much as 6 months on average in the case of tourism to French Polynesia. Moreover, the purchasing behavior for such services is also usually long, taking up to several days. In the while, firms such as airlines set prices according to the available capacity to sell. Their latest technologies of data collection and computing allow real time pricing based on level of demand and individual level tracking of sites visited and actions taken for example. Price variations resulting from such pricing scheme are particularly salient at the stage of choice in the buying process. This research aims at exploring whether perceived fairness of such practices relate to price and pricing dimensions.

Both price offered and the rationale for offering a certain price may lead to perceptions of fairness (Xia et al., 2004) and to negative consequences for the consumer, such as dissatisfaction, distrust (Chapuis, 2012), and lower intentions to repurchase (e.g., Oliver and Swan, 1989) and by extension for the seller (e.g., Campbell 1999). Price fairness is a buyer's judgment of a seller's price (Haws and Bearden, 2006). Although consumers are able to quickly identify unfair situations, it is conversely more difficult for consumers to assess whether a policy is fair (Bolton et al., 2003; Taylor and Kimes, 2010).

However, the relationships between consumers' perceptions of pricing fairness and their price fairness perceptions are a two-way causality. Pricing fairness can be inferred from certain types of outcomes and be a consequence of perceived price fairness (Garbarino and Maxwell, 2010). The process that leads to the final price may play a significant role in price fairness perceptions. The effect of price perceptions of price fairness can be mediated by perceived pricing fairness (Xia et al., 2010). The purpose of this research is to understand the interactions between consumers' perceptions of price fairness and pricing fairness. The research has implications for future researches and for managers.

The structure of the paper is the following. The first section reviews the literature. The second section presents an exploration study. The third section discusses and draws the implications of the results. 


\section{A theoretical background of perceived fairness}

People judge price as an outcome as well as a process, referring to equity theory and procedural justice respectively.

\subsection{Price fairness}

Equity judgment considers the comparison the ratios of inputs and outputs of each partner within a relationship or with another person as a reference. Adams (1965) defines a state of inequity when one perceives that the ratio of ones inputs and outputs is not equal to that of the other. Equity theory attempts to explain transactional satisfaction in terms of perceptions of fair or unfair distributions of resources within interpersonal relationships. Then, the breakdown of the proportionality results in the feeling of being treated unfairly. Individuals who perceive themselves in inequitable relationships will experience distress because they value fair treatment. They are motivated to reduce the inequity within the relationship either by distorting contributions (e.g. trust) and/or rewards (e.g. satisfaction) in their own minds and altering costs and/or benefits (e.g. complaining) or by leaving the relationship. Price fairness is a consumer's assessment and associated emotions of whether the difference (or lack of difference) between a seller's price and the price of a comparative other party is reasonable, acceptable, or justifiable (Xia et al, 2004). Price fairness judgments may be based on previous prices, competitor prices, and profits (Bolton et al., 2003).

\subsection{Pricing fairness}

Attribution theory explores the cognitive perceptions of individuals when they "attribute" causes to events (Weiner, 1985). Inferences are important determinants of consumers' affective and behavioral responses to price discriminations. Procedural justice refers to the perceived fairness of policies, procedures, and criteria used by decision makers by which ends are accomplished (Thibaut and Walker, 1975). Pricing fairness considers the comparison of the pricing process with social norms (Cox, 2001). In this case, the social norms are the rules that the community agrees sellers should follow when setting prices (Garbarino and Maxwell, 2010). For ex., Rohlfs and Kimes 
(2007) explored the consumers' perceptions of the fairness of blended and non-blended best-available price policies in the hospitality industry. As a result of a day-to-day seasonal price discrimination, the room price changes from night to night in the nonblended policy. The offer is economically equivalent to quoting a single average rate for a multiple-night stay. The authors found that respondents rated average price policy less fair than the non-blended prices. Whether or not a pricing scheme improves the firm's profit, the attribution of a negative motive to it will cause the perception of pricing (un)fairness (Campbell, 1999). From the above framework, this note posits that

Hypothesis 1: Perceptions of fairness is a multidimensional concept, dealing with price and pricing fairness.

If so, how do they interact? Pricing fairness can be inferred from perceived price fairness. A perceived fair price may increases the perception of a fair pricing scheme (Kimes and Wirtz, 2003). Buyers, having perceived that the rules pertaining to the price have not been followed, will infer that the rules of pricing have also not been followed (Maxwell, 2002).

On the other way, perceptions of price fairness may be affected not only by the price paid but also by the rules that were used to set the prices. Kimes and Wirtz (2003, p. 128) assumes that a fair price is one that results from a fair pricing rule. However, a price can break the equity ratio while the pricing policy used to set it does not break a norm, or conversely. For example, advance purchase discount is quit rational and accepted but yields lower outcomes (higher prices to people who book late compensated by more flexibility and/or less uncertainty about the value of the product) to people who book at the last moment. Promotion fairness appears as a mediating factor between perceived input and price fairness perceptions (Xia et al., 2010). Finally, pricing fairness can constitute a unique source of fairness alongside price fairness considerations. Therefore:

Hypothesis 2a: There is a positive relationship between consumers' perceptions of pricing fairness and their perceptions of price fairness.

Hypothesis 2b: Perceptions of price and pricing fairness influence consumer satisfaction. 


\section{Empirical Analysis in the tourism industry}

This section aims to empirically test the interactions of price fairness and pricing fairness in a survey-based study with a Structural Equation Modeling (SEM). Its first part designs the experiment and presents the latent variables. The second provides the empirical results of various models.

\subsection{Experimental design}

A common research method in studies of fairness is to ask participants of experiments to imagine themselves in hypothetical situations. Five percent of the November 2009 flow of passengers $(n=250)$ were conveniently chosen at the queues of outbound flights from Tahiti International Airport (PPT) ${ }^{1}$. A scenario concerning an airline which makes a pricing decision that questions the fairness of the transaction is offered to each participant. Price discriminations are manipulated within scenarios in a between-subject experiment ${ }^{2}$. The manipulation of a competitor's price along with a price increase decided by the airline leads to two situations expected to trigger fairness perceptions. First, the participant confronts a price increase during the buying process (manipulation to USD 2,000). Second, it provides a relative position, as the participant encounters a price increase higher or lower than what he would afford on the market (manipulation to USD 1,500 or 2,500). Having read a randomly assigned scenario, participants answered several questions about the fairness of their situation (Table 2).

A confirmatory factor analysis (CFA) investigates the validity of the constructs. The procedure checks whether the measurements reflected the latent variables by assessing the convergence validity according to the goodness-of-fit and factor loadings statistics (Gerbing and Anderson, 1988).

The price fairness and pricing fairness as endogenous constructs are measured using 5-point Likert-type scales, all anchored at endpoint from "strongly disagree" $=1$ to

${ }^{1}$ The descriptive statistics are available from the author. The tests address the bias of nonresponse, law of distribution, representativeness of the sample, relationship between variables and characteristics of participants.

${ }^{2}$ The method to ensure the realism of the data offered in the scenario, its test of realism as well as the manipulations checks, are available from the author. 
"strongly agree"=5. The scales are adapted from Campbell (1999) and Xia et al. (2010) modifying them to fit the study settings. The reliability for the price fairness is high (Jöreskog's Rho=0.88). The scale for the pricing fairness is reliable $(\mathrm{Rho}=0.75)$. The overall satisfaction with the reservation process is measured by two items based on the studies of Oliver and Swan (1989) (anchored "strongly disagree"=1 to "strongly agree" $=5)$. The scale is reliable $(\mathrm{Rho}=0.75)$.

Table 2: Constructs and descriptive statistics of items $(N=250)$

Construct Item description

Mean Std.Dev. Skewness Kurtosis - 3

Price $\quad x_{1}$ : I paid the right price for my ticket

Fairness
2.53
0.84
0.09
$-0.44$

$x_{2}$ : The price that I was charged for my ticket was acceptable
2.62
1.03
0.20
$-0.43$

Pricing $\quad x_{3}$ : I was treated fairly by the airline's pricing process

Fairness
2.58
0.97
0.15
$-0.59$

$x_{4}$ : The price that I was charged for my ticket was reasonable
2.43
0.96
0.38
$-0.50$

Satisfaction $\quad x_{5}$ : Overall, I am satisfied with the airline's reservation service

$$
\begin{array}{llll}
2.80 & 0.95 & -0.05 & -0.67
\end{array}
$$

$x_{6}$ : My experience with the reservation process of the airline is better than expected

$$
\begin{array}{llll}
2.92 & 1.01 & -0.31 & -1.00
\end{array}
$$

The CFA model is estimated using a bootstrap procedure available in AMOS (16). The related goodness-of-fit statistics are large $\left(\chi_{(6)}^{2}=12.63, p=0.05 ;\right.$ AGFI $=0.94$ and RMSEA=0.066). All standardized residual covariances were lower than 2 . Table 3 presents the standardized estimates of the factor loadings and other statistics. An evidence of internal consistency has stemmed from Jöreskog's Rhos between 0.75 and 0.88. As evidence of convergent validity, all measurement factor loadings were significant (all $t$-values $>2$ ). All items loaded only on their respective factor. 
Table 3: CFA

\begin{tabular}{lcccc}
\hline Construct (AVE) & Item & $\lambda$ & $t$-value & $R^{2}$ \\
\hline $\begin{array}{l}\text { price fairness } \\
(0.79)\end{array}$ & $x_{1}$ & 0.89 & $16.12^{* * *}$ & 0.79 \\
& $x_{2}$ & 0.89 & $16.06^{* * *}$ & 0.78 \\
pricing fairness & $x_{3}$ & 0.77 & $13.01^{* * *}$ & 0.60 \\
$(0.61)$ & $x_{4}$ & 0.78 & $13.15^{* * *}$ & 0.61 \\
Satisfaction & $x_{5}$ & 0.82 & $10.68^{* * *}$ & 0.68 \\
$(0.60)$ & $x_{6}$ & 0.73 & $9.80^{* * *}$ & 0.53 \\
\hline$\chi_{(6)}^{2}=12.63 ; \chi_{\text {/d.f. }}^{2}=2.10 ; p=.05 ;$ AGFI=0.94; RMSEA $=0.066$ \\
\hline
\end{tabular}

Legend: $\lambda$ are the standardized factor loadings. ${ }^{* * *}$ indicates $p$-values lower than .01 , $\mathrm{AVE}=$ average variance extracted, $\mathrm{AGFI}=$ adjusted goodness-of-fit index, RMSEA $=$ root mean square error of approximation.

\subsection{Results}

\subsubsection{The discriminant validity of the constructs}

The study explicitly addresses the dimensionality of fairness constructs taking into account the random error. The hypothesis 1 assumes that fairness consists of distinct, although possibly interrelated, price fairness and pricing fairness judgments. The convergence validity of a two-dimensional construct of fairness is not rejected as the items loaded only on their respective construct. The discriminant validity presumes that a construct should share more variance with its measures than it shares with other constructs of the same causality level within the model. The perception that a price is unfair is expected to trigger the judgment of the pricing process as unfair, suggesting a positive coefficient between them and vice versa $(\mathrm{H} 2: \phi>0)$. The significant positive correlation $(\phi=.74 ; p<.01)$ between the price fairness and pricing fairness is lower than the root of the average variance extracted of each factor (respectively .79 and .61 Fornell and Lacker, 1981). A formal test of the discriminant validity assumes as null hypothesis that the two constructs are exactly similar $(\phi=1.00)$. Relaxing this constraint 
leads to a significant decrease in the $\chi^{2}\left(\Delta \chi_{(1)}^{2}=42.54 ; p<.01\right)$ meaning a better goodnessof-fit of the model rejecting the null hypothesis. So, there is evidence to reject the absence of discrimination and support $\mathrm{H} 1$ and H2a that price fairness and pricing fairness are two distinct, positively interrelated constructs.

\subsubsection{Perceptions of price fairness and pricing fairness influence satisfaction}

Model 1 in Table 4 shows that $32 \%$ of the variance of satisfaction is explained by price fairness and pricing fairness. However, only the influence of pricing fairness is significant $(\beta=0.74, t=4.25)$ while price fairness is not $(\beta=-0.22, t=-1.64)$.

Table 4: Standardized parameter estimates of models

\begin{tabular}{|c|c|c|c|c|c|c|}
\hline Models & goodness-of-fit & & Path & Sd Est & $t$-value & $R^{2}$ \\
\hline \multirow[t]{4}{*}{ Model 1} & $\chi_{(6)}^{2}=12.63 ; p=.05$ & & & & & 0.32 \\
\hline & Price fairness & $\langle-\rangle$ & Pricing Fairness & 0.74 & $7.42^{* * *}$ & \\
\hline & Price fairness & $\rightarrow$ & Satisfaction & -0.22 & -1.64 & \\
\hline & Pricing Fairness & $->$ & Satisfaction & 0.72 & $4.25^{* * *}$ & \\
\hline \multirow[t]{3}{*}{ Model 2a } & $\chi_{(7)}^{2}=38.1 ; p<.00$ & \multicolumn{2}{|c|}{$\Delta \chi_{(1)}^{2}=25.5 ; p<.00$} & & & 0.12 \\
\hline & Price fairness & $<->$ & Pricing Fairness & 0.75 & $7.58^{* * *}$ & \\
\hline & Price fairness & $->$ & Satisfaction & 0.35 & $4.56^{* * *}$ & \\
\hline \multirow[t]{3}{*}{ Model 2b } & $\chi_{(7)}^{2}=15.5 ; p=.03$ & \multicolumn{2}{|c|}{$\Delta \chi_{(1)}^{2}=2.8 ; p=.09$} & & & 0.27 \\
\hline & Price fairness & $\langle->$ & Pricing Fairness & 0.72 & $7.35^{* * *}$ & \\
\hline & Pricing Fairness & $->$ & Satisfaction & 0.52 & $5.62^{* * *}$ & \\
\hline \multirow[t]{2}{*}{ Model 3} & $\chi_{(13)}^{2}=77.68 ; p<.00$ & & & & & 0.14 \\
\hline & Fairness & $->$ & Satisfaction & 0.38 & $4.82^{* * *}$ & \\
\hline
\end{tabular}

Legend: Sd Est are the standardized estimates of covariance (<->) and path (->). indicates $p$-values lower than .01 . 
Up to this point, the analysis indicates a strong support for the H2b. Two competing models are also assessed for completeness especially if only one factor is considered. The Model 2 a considers the influence of price fairness only. Then price fairness is a significant determinant of consumer satisfaction $(\beta=0.35, t=4.56)$ but the model has a low explanatory power $\left(R^{2}=.12\right)$. The Model $2 \mathrm{~b}$ considers the influence of pricing fairness separately. The total effect of pricing fairness on satisfaction is positive and significant $\left(\beta_{31}=0.52, t=5.62\right)$ with $R^{2}=.27$. Moreover, the $\Delta \chi^{2}$ test shows that not taking into account price fairness does not reduce significantly the goodness of fit, as the model $2 \mathrm{~b}$ is nested with the model $1\left(\Delta \chi_{(1)}^{2}=2.8 ; p=.09\right)$. Lastly, the Model 3 provides an indirect test of $\mathrm{H} 1$. The model assumes that a single variable fairness from the 4 items of price fairness and pricing fairness. The results show that fairness is a significant determinant of consumer satisfaction $(\beta=0.38, t=4.82)$ but the model has a low explanatory power $\left(R^{2}=.14\right)$, similar to the model $2 \mathrm{a}$. This competing model was less fitted to the data than the proposed model $1\left(\chi_{(38)}^{2}=77.68, p<.01\right)$. Overall, the results support that both perceptions of fairness influence consumer satisfaction.

\section{Discussion and managerial implications}

Overall, the analysis is consistent with the hypotheses $\mathbf{1}$ and $\mathbf{2}$ that fairness is a two-dimension construct and an antecedent of satisfaction. The respondents, who had experienced a price increase during the buying process, were concerned with fairness in the price as well as in the pricing process as predicted. The mains contributions of the research are distinguishing perceptions of price fairness and of pricing fairness, triggered during the buying process.

First and consistent with the current trend in consumer studies (Xia et al., 2010), the theoretical conceptualization of perceptions of price fairness and pricing fairness appears to be statistically significant. This is consistent with Maxwell's (2002) results that price fairness and pricing fairness are two distinct concepts with a positive two-way relationship. The findings mean that fairness perceptions are not only induced solely by the fact that a consumer has to pay a price higher than previously promised but also by the pricing procedure used to set that price. The results are also consistent with the Oliver and Swan's (1989) conclusion that fairness emerges as the dominant determinant 
of consumer satisfaction. The study shows that using two constructs increase the explanatory power of the model.

Second as a main result, the study shows that perceptions of fairness appear early, during the buying process, not only at the time of consumption. This is consistent with both Bolton et al. (2003) and Xia et al. (2004) that fairness judgments consider self-comparison and other-comparison. Overall, the study has implications for researchers and practitioners alike.

The findings suggest that research working with only one construct of fairness about price as an outcome as well as a process is limiting the empirical relationships. For example, Choi and Mattila (2004) and Lindenmeier and Tscheulin (2008) found that the lowest satisfaction is associated with unfavorable price comparison. The findings here extend our knowledge and are consistent with their results by showing how price and pricing fairness perceptions affects satisfaction after a price discrimination. Moreover, the proposed framework may help explain the inconsistent results across studies.

Implications for managers are twofold. The managers should act very early in the buying process and do not wait hoping the customer will not meet (during the consumption) another who pays a lower price. Second, managers should adapt the information they provide about any price difference in any situation as perceptions of fairness may occur at the price or pricing level. The effect of perceived pricing fairness on consumers' price fairness perceptions suggests that managers should be concerned as the whether consumers are actually paying attention to and understand the price restrictions (Xia et al., 2010). Managers should frame the price tag to lessen the adverse impact at the transactional level. They should explain the rational of the pricing scheme at the relationship (social norms) level. In the sample, this is the more efficient solution as, when pricing fairness goes up by one standard deviation, satisfaction increase on average by .72 standard deviation. While increasing price fairness by one standard deviation does not significantly increase satisfaction. 


\section{Conclusion}

This research contributes to introduce a distinction between perceptions of price and pricing fairness. Moreover, the results show that those perceptions occurring during the buying process have an impact on satisfaction. The results from a sample of 250 passengers at an international luxury destination supported that experiencing price discrimination while booking a flight leads to perceptions of fairness having an influence on consumer satisfaction.

The caveats of the limitations of this research are warranted. While scenarios may not be perfect, they are useful for exploratory purpose. An implication of the study is that researchers should carefully distinguish the source of perceived fairness. However, the current study is based on scales already available in the literature without formally developing a dedicated scale according to the dimensions of the fairness concept. This calls for a future research to assess the validity of a more relevant instrument.

\section{References:}

Adams, J.S. (1965). Inequity in social exchange. In L. Berkowitz (Ed.), Advances in experimental social psychology, 2, 267-299. New York: Academic Press.

Bolton, L.E., Warlop, L. and Alba, J. (2003). Consumer perceptions of price (un)fairness. Journal of Consumer Research, 29(4), 474-492.

Campbell, M.C. (1999). Perceptions of price unfairness: Antecedents and consequences. Journal of Marketing Research, 36(May), 187-199.

Chapuis, J.M. (2012). Perceived fairness and trust in consumer's reactions to revenue management, International Journal of Revenue Management, in press.

Choi, S. and Mattila, A.S. (2004). Hotel revenue management and its impact on customers' perceptions of fairness, Journal of Revenue and Pricing Management, 2(4), 303-315.

Cox, J.L. (2001). Can differential prices be fair? Journal of Product and Brand Management, 10(5), 264-275.

Garbarino, E. and Maxwell, S. (2010). 'Consumer response to norm-breaking pricing events in e-commerce', Journal of Business Research, 63(9), 1066-1072. 
Gerbing, D.W. and Anderson, J.C. (1988). An updated paradigm for scale development incorporating unidimensionality and its assessment. Journal of Marketing Research, 25(May), 186-92.

Haws, K.L. and Bearden, W.O. (2006). Dynamic pricing and consumer fairness perceptions. Journal of Consumer Research, 33(3), 304-311.

Kimes, S.E. and Wirtz, J. (2003). Has revenue management become acceptable? Findings from an international study on the perceived fairness of rate fences. Journal of Service Research, 6(2), 125-137.

Lindenmeier, J. and Tscheulin, D.K. (2008). The effects of inventory control and denied boarding on customer satisfaction: The case of capacity-based airline revenue management. Tourism Management, 29(1), 32-43.

Maxwell, S. (2002). Rule-based price fairness and its effect on willingness to purchase. Journal of Economic Psychology, 23, 191-212.

Oliver, R.L. and Swan, J.E. (1989). Consumer perceptions of interpersonal equity and satisfaction in transactions: A field survey approach. Journal of Marketing, 53(April), 21-35.

Rohlfs, K.V. and Kimes, S.E. (2007). Customers' perceptions of best available hotel rates. Cornell Hotel and Restaurant Administration Quarterly, 48(2), 151-162.

Taylor, W.J. and Kimes, S.E. (2010) 'How hotel guests perceive the fairness of differential room pricing', Cornell Hospitality Report, 10(2).

Thibaut, J. and Walker, L. (1975). Procedural justice: A psychological analysis. Hillsdale, NJ: Lawrence Erlbaum Associates.

Weiner, B. (1985). An attributional theory of achievement motivation and emotion. Psychological Review, 92, 548-573.

Xia, L., Monroe, K. B. and Cox, J.L. (2004). The price is unfair! A conceptual framework of price fairness perceptions. Journal of Marketing, 68(October), 1-15.

Xia, L., Kukar-Kinney, M. and Monroe, K.B. (2010). Effects of Consumers' Efforts on Price and Promotion Fairness Perceptions. Journal of Retailing, 86(1), 1-10. 